\title{
Photodimerisation of pyrrolizin-3-one
}

\author{
Xavier L.M. Despinoy and Hamish McNab* \\ Department of Chemistry,The University of Edinburgh, \\ West Mains Road,Edinburgh EH9 3JJ, UK \\ E-mail: H.McNab@ed.ac.uk
}

\section{Dedicated to Professor Gurnos Jones on the occasion of his $70^{\text {th }}$ birthday}

(received 17 Apr 00; accepted 20 Aug 00; published on the web 28 Aug 00)

\begin{abstract}
Irradiation of pyrrolizin-3-one 1 in dilute solution using a $125 \mathrm{~W}$ mercury lamp gives three [2+2] dimers assigned as $\mathbf{9 , 1 0}$, and $\mathbf{1 1}$ by comparison of their spectra with those of model compounds. The ratio of these dimers is dependent on the solvent and on the presence or absence of a triplet sensitiser.
\end{abstract}

Keywords: Photodimerisation, pyrrolizin-3-one, triplet sensitization, tetrahydrodiazacyclobutadipentalones

\section{Introduction}

Although pyrrolizin-3-one 1 was first made nearly 30 years ago, ${ }^{1}$ very little is known of its chemical properties. $^{2}$ Only hydrogenation ${ }^{1}$ and hydrochlorination ${ }^{3}$ reactions of the 1,2 -double bond, reactions with nucleophiles ${ }^{1-3}$ and Wittig olefination at the carbonyl group ${ }^{1}$ have been reported. In this paper we describe the results of a series of experiments in which the photochemistry of $\mathbf{1}$ was investigated. $\alpha, \beta$-Unsaturated enone units of 5 -membered ring heterocycles are known to undergo a variety of photochemical reactions. For example the behaviour of thiophen-3-ones ${ }^{4} 2(\mathrm{X}=\mathrm{S})$ and the corresponding furanones ${ }^{5} 2(\mathrm{X}=\mathrm{O})$ is dominated by $[2+2]$ dimerisation and photoreduction reactions. In contrast the corresponding pyrrolones 2 ( $\mathrm{X}=\mathrm{NR}$ ) show clean photochemical behaviour only when $\mathrm{R}$ is electronwithdrawing. ${ }^{6}$

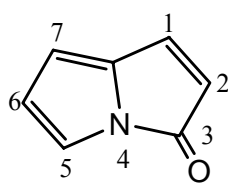

1

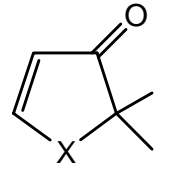

2

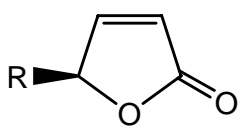

3 
In the photodimerisation reactions, four possible cycloadducts may be formed ['head-tohead' $(H H)$ syn and anti; 'head-to-tail' (HT) syn and anti (Figure 1)] but such reactions are generally selective and only some of the cycloadducts are usually observed. ${ }^{4,5}$ The selectivity is dependent on experimental conditions such as the nature of the solvent and the presence or absence of triplet sensitisers.

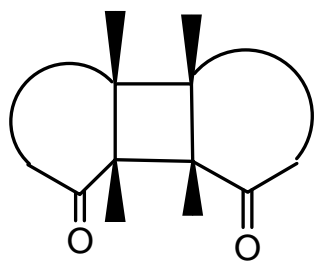

HH-syn

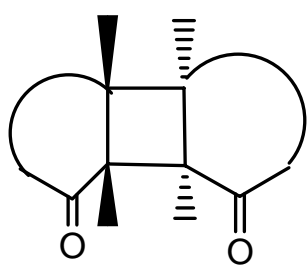

HH-anti

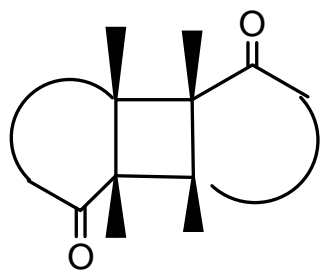

HT-syn

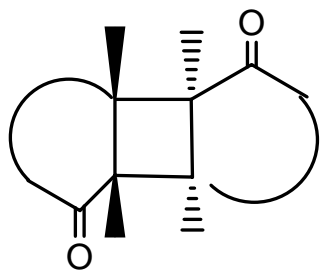

HT-anti

\section{Figure 1}

Of particular interest butenolides ${ }^{7} \mathbf{3}$ undergo regiospecific conjugate $C$-addition of alcohols under photolytic conditions. If the pyrrolizinones were to follow this pathway a hydroxymethyl group would be introduced at the 1-position, thereby creating in a single step the carbon skeleton of the necine bases of many important pyrrolizidine alkaloids.

\section{Results and Discussion}

Irradiation of 1 (125 W mercury lamp) in methanolic solution gave, after $18 \mathrm{~h}$, a mixture containing three products in approximately equal amounts. These were all assigned as $[2+2]$ cycloadducts 4 and/or 5 from the NMR spectrum of the crude photolysate, owing to the disappearance of the 'alkene'-type proton signals at $\delta \mathrm{H} 7.04$ and 5.63 (respectively $\mathrm{H}-1$ and $\mathrm{H}-2$ ) and the appearance of signals at $\delta \mathrm{H} 4.09$ and 3.71 in the saturated region of the spectrum. Corresponding changes in the ${ }^{13} \mathrm{C}$ NMR spectrum were noted (see Experimental section). The dimers could be distinguished by subtle differences in their NMR spectra (e.g. for the protons derived from $\mathrm{H}-7$ of the precursor, dimer $\mathrm{A}$ had $\delta \mathrm{H}$ 6.18; dimer $\mathrm{B}$ had $\delta \mathrm{H} \mathrm{5.86}$; dimer $\mathrm{C}$ had $\delta \mathrm{H}$ 6.07), but such differences were insufficient for rigorous assignment of the structures (see below). No suitable crystals could be obtained for X-ray analysis.

The relative ratio of dimers A-C proved to be strongly dependent on reaction conditions (Table 1). The presence of a slight excess of benzophenone (a well-known triplet sensitiser) had two effects. The time required for the reaction was significantly reduced and photodimers $\mathrm{A}$ and $\mathrm{B}$ accounted for $>80 \%$ of the product mixture with the dimer $\mathrm{C}$ present in very small amount $(5 \%)$. 

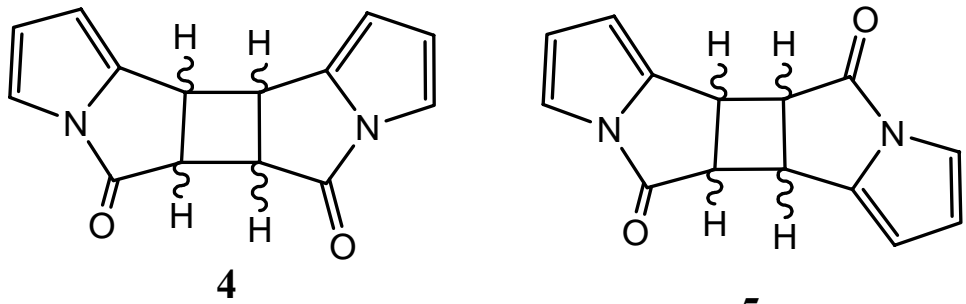

5

This suggests that dimers $\mathrm{A}$ and $\mathrm{B}$ are formed via the triplet state and that dimer $\mathrm{C}$ is formed via the singlet excited state of pyrrolizin-3-one 1. From this experiment, pure samples of photodimers $\mathrm{A}$ and $\mathrm{B}$ were isolated by chromatography in yields of $27 \%$ and $33 \%$ respectively. The use of isopropyl alcohol or acetonitrile as solvent gave a preponderance of dimer C. No photoaddition of the solvent was observed when methanol or propan-2-ol were used as solvent in contrast to the situation with butenolides 3 and so the potential photoaddition route to necine bases (discussed above) is not viable under these conditions. ${ }^{7}$

Table 1. Products from irradiation of $\mathbf{1}(125 \mathrm{~W}$ mercury lamp, room temperature)

\begin{tabular}{cccccc}
\hline Solvent & Time/h & $\begin{array}{c}\text { Dimer A } \\
(\%)\end{array}$ & $\begin{array}{c}\text { Dimer B } \\
(\%)\end{array}$ & $\begin{array}{c}\text { Dimer C } \\
(\%)\end{array}$ & $\begin{array}{c}\text { Recovered } \\
1(\%)\end{array}$ \\
\hline $\begin{array}{c}{\left[{ }^{2} \mathrm{H}_{4}\right] \text { Methanol }} \\
\text { Methanol/ }\end{array}$ & 18 & 31 & 31 & 25 & 12 \\
$\begin{array}{c}\text { benzophenone } \\
\text { Propan-2-ol }\end{array}$ & 7.5 & 39 & 47 & 5 & 9 \\
{$\left[{ }^{2} \mathrm{H}_{3}\right]$ Acetonitrile } & 16 & 7 & 12 & 44 & 36 \\
\hline
\end{tabular}

In attempting to assign structures to the three photodimers, it was not possible to use unambiguous NMR methods because of the symmetry of the molecules and because the resonances of all four cyclobutane protons overlap when the spectra are recorded at $200 \mathrm{MHz}$. We have therefore resorted to assignments based on chemical shift analogies with related model compounds, bearing in mind that these are subjective (in particular when only limited data are available) and only tentative assignments can be made at this time. 1,2-Dihydropyrrolizin-3-one $\mathbf{6}$ (whose ${ }^{1} \mathrm{H}$ NMR spectrum has been assigned) and the known $H H$ dimers $\mathbf{7}$ and $\mathbf{8}$ (which form spontaneously and whose structures have been rigorously determined by X-ray crystallography ${ }^{8}$ ) were used as primary models together with literature data ${ }^{4,5}$ for the photodimers of $\mathbf{2}(\mathrm{X}=\mathrm{S})$ and 3. 


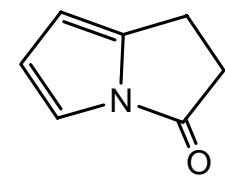

6

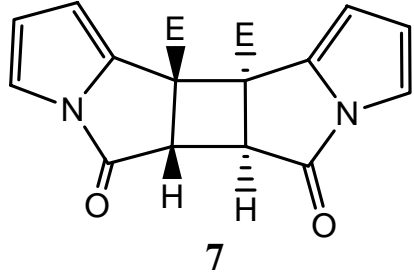

7

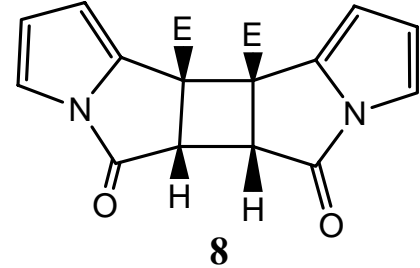

$\left(\mathrm{E}=\mathrm{CO}_{2} \mathrm{Me}\right)$

We consider first the data for the cyclobutane rings which show significant differences between dimer $\mathrm{A}$ and dimers $\mathrm{B}$ and $\mathrm{C}$ [dimer $\mathrm{A}$ has $\delta \mathrm{H} 3.71(4 \mathrm{H}, \mathrm{m})$; dimer $\mathrm{B}$ has $\delta \mathrm{H} 4.09(4 \mathrm{H}$, $\mathrm{m})$; dimer $\mathrm{C}$ has $\delta \mathrm{H} 4.09(4 \mathrm{H}, \mathrm{m})]$. Our data for 7 and 8 suggest that cyclobutane protons adjacent to the ring carbonyl groups ( $\delta \mathrm{H} 4.03$ and 4.36 respectively) are shielded by ca. 0.3 p.p.m. in the anti-HH-adduct relative to the syn-HH adduct. Margaretha's data on anti dimers of $\mathbf{2}$ and $\mathbf{3}$ show relatively little difference between the chemical shifts of the corresponding protons of $H H$ and $H T$ adducts (maximum D $\delta H 0.13$ p.p.m.). ${ }^{4,5}$ These data suggest that dimer $\mathrm{A}$ is an anti adduct and dimers $\mathrm{B}$ and $\mathrm{C}$ are syn adducts.

Chemical shift data for the 'pyrrole' protons of the dimers and the model compounds 6-8 are given in Table 2. The presence of the ester function in $\mathbf{7}$ and $\mathbf{8}$ apparently has a deshielding effect on the adjacent protons (H-7) of ca. 0.3 p.p.m. over and above the effect of the dimerisation, but the ester group would be expected to have relatively little influence on the remainder of the spectrum. All the 'pyrrole' protons of the anti-dimer 7 are deshielded relative to the dihydropyrrolizinone $\mathbf{6}$, whereas the effect of the syn configuration in $\mathbf{8}$ is to shield protons derived from H-5 and H-6. Because dimer A (already thought to be anti) shows quantitatively comparable deshielding of H-5 and H-6 to that of the known anti-dimer7 it is likely that this isomer is also an anti-HH dimer 9. Dimers B and $\mathrm{C}$ show rather similar shielding of H-5 and H-6 to that of $\mathbf{8}$ and are difficult to distinguish, but the overall fit with $\mathbf{8}$ is better for dimer B particularly when the expected additional deshielding of $\mathrm{H}-7$ in $\mathbf{8}$ is taken into account. Dimer B is probably therefore the syn-HH compound $\mathbf{1 0}$ and dimer $\mathrm{C}$ is the syn-HT adduct $\mathbf{1 1 .}$

Table 2. Selected ${ }^{1} \mathrm{H}$ NMR data for the model compounds 6-8 and dimers A-C

Compound $\delta \mathrm{H}(5)^{*}$ (difference from $\delta \mathrm{H}(6)^{*}$ (difference from $\delta \mathrm{H}(7)^{*}$ (difference from corresponding signal of 6)corresponding signal of 6)

\begin{tabular}{llll}
\hline $\mathbf{6}$ & 7.00 & 6.42 & 5.93 \\
7 (anti isomer) & $7.17(0.17)$ & $6.54(0.12)$ & $6.37(0.44)$ \\
$\mathbf{8}$ (syn isomer) & $6.90(-0.10)$ & $6.33(-0.09)$ & $6.13(0.20)$ \\
Dimer A anti-HH & $7.15(0.15)$ & $6.56(0.14)$ & $6.18(0.25)$ \\
Dimer B syn-HH & $6.89(-0.11)$ & $6.30(-0.12)$ & $5.86(-0.07)$ \\
Dimer C syn-HT & $6.80(-0.20)$ & $6.32(-0.10)$ & $6.07(0.14)$ \\
\hline
\end{tabular}

*Numbering scheme based on that of the parent pyrrolizinone $\mathbf{1}$. 


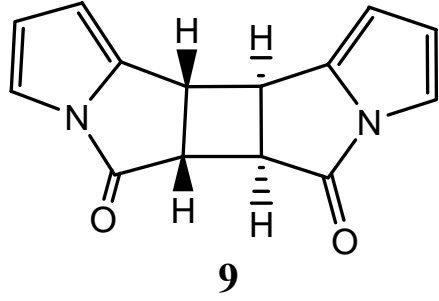

dimer A anti-HH

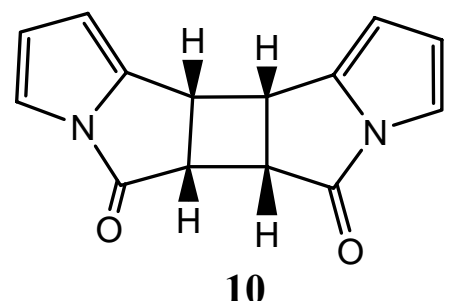

dimer B syn-HH

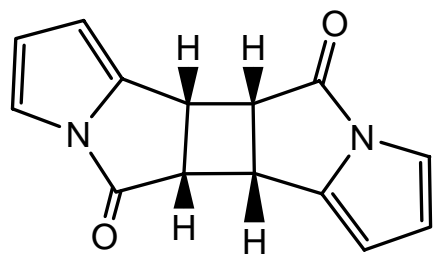

11

dimer $\mathrm{C}$

syn-HT

Finally, it is worthwhile to consider the structural implications of these tentative assignments on the results of the solvent and sensitiser experiments (Table 1). The proportions of dimers A and B (anti- and syn- $\mathrm{HH}$ respectively) follow similar trends [major products in methanol (with or without sensitisation), minor products in propan-2-ol and in acetonitrile] and so it is consistent that they are probably structurally related. $H H$-Dimers are predicted to be favoured over $H T$ dimers by frontier molecular orbital (FMO) arguments. ${ }^{9}$ In the photosensitised dimerisation of dimethylthymine, ${ }^{10}$ the proportion of syn-HT dimer is reduced and that of syn-HH dimer is increased relative to the unsensitised case - as is found in our work. On the other hand there is considerable evidence that formation of $\mathrm{HH}$ dimers is favoured in more polar solvents (e.g. acetonitrile) (ref. 5 and references therein) and this observation remains at variance with our structural assignments.

\section{Experimental Section}

General Procedures. ${ }^{1} \mathrm{H}$ and ${ }^{13} \mathrm{C}$ NMR spectra were recorded at 200 (or 250) and 50 (or 63) $\mathrm{MHz}$ respectively for solutions in $\left[{ }^{2} \mathrm{H}\right]$ chloroform unless otherwise stated. Mass spectra were obtained under electron impact (EI) ionisation conditions.

\section{Photodimerisation of pyrrolizin-3-one 1 in the presence of benzophenone}

A solution of pyrrolizin-3-one 1 (195 mg, $1.6 \mathrm{mmol})$ and benzophenone $(338 \mathrm{mg}, 1.8 \mathrm{mmol})$ in methanol $(20 \mathrm{~mL})$ contained in a quartz immersion well was irradiated with a $125 \mathrm{~W}$ mercury lamp for $16 \mathrm{~h}$ at room temperature. No light filters were used. The solvent was removed and the reaction products were separated by dry flash chromatography on silica (using hexane/ethyl acetate as eluents). This yielded recovered benzophenone (321 mg), followed by anti-7,8-dioxo7,7a,7b,8-Tetrahydro-6a,8a-diaza-cyclobuta[1,2-a; 4,3-a']dipentalene (9) (dimer A) (53 mg, $27 \%$ ) as a colourless solid, $\mathrm{mp} 250-251{ }^{\circ} \mathrm{C}$ (ethyl acetate) (Found: $\mathrm{C}, 70.05 ; \mathrm{H}, 4.2 ; \mathrm{N}, 11.5$. $\mathrm{C}_{14} \mathrm{H}_{10} \mathrm{~N}_{2} \mathrm{O}_{2} .0 .05 \mathrm{H}_{2} \mathrm{O}$ requires $\left.\mathrm{C}, 70.3 ; \mathrm{H}, 4.2 ; \mathrm{N}, 11.75 \%\right) ;{ }^{1} \mathrm{HNMR} \delta 7.15\left(2 \mathrm{H}, \mathrm{dd},{ }^{3} J=3.0 \mathrm{~Hz}\right.$ and $\left.{ }^{4} \mathrm{~J}=1.1 \mathrm{~Hz}\right), 6.56\left(2 \mathrm{H}, \mathrm{t},{ }^{3} \mathrm{~J}=3.0 \mathrm{~Hz}\right), 6.18\left(2 \mathrm{H}, \mathrm{d},{ }^{3} \mathrm{~J}=3.0 \mathrm{~Hz}\right)$ and $3.71(4 \mathrm{H}, \mathrm{m}) ;{ }^{13} \mathrm{CNMR} \delta$ 170.1 (quat), 139.9 (quat); 120.0, 112.1, 105.7, 47.3 and 39.2; m/z 239 (13), 238 (M $\left.\mathrm{M}^{+}, 53 \%\right), 209$ 
(4), 180 (5), 155 (8), 120 (67), 119 (100), 91 (55), 64 (32) and 63 (30) and syn-7,8-dioxo7,7a,7b,8-Tetrahydro-6a,8a-diaza-cyclobuta[1,2-a; 4,3-a']dipentalene (10) (dimer B) (65 mg, $33 \%$ ) as a colourless solid, mp 246-247 ${ }^{\circ} \mathrm{C}$ (toluene) (Found: $\mathrm{C}, 70.2 ; \mathrm{H}, 4.2 ; \mathrm{N}, 11.45$. $\mathrm{C}_{14} \mathrm{H}_{10} \mathrm{~N}_{2} \mathrm{O}_{2}$ requires $\left.\mathrm{C}, 70.6 ; \mathrm{H}, 4.2 ; \mathrm{N}, 11.75 \%\right) ;{ }^{1} \mathrm{HNMR} \delta 6.89\left(2 \mathrm{H}, \mathrm{d},{ }^{3} \mathrm{~J}=3.1 \mathrm{~Hz}\right), 6.30(2 \mathrm{H}$, $\left.\mathrm{t},{ }^{3} \mathrm{~J}=3.1 \mathrm{~Hz}\right), 5.86\left(2 \mathrm{H}, \mathrm{d},{ }^{3} \mathrm{~J}=3.1 \mathrm{~Hz}\right)$ and $4.09(4 \mathrm{H}, \mathrm{m}) ;{ }^{13} \mathrm{CNMR} \mathrm{d} 168.6$ (quat), 137.0 (quat); 119.4, 112.2, 106.4, 45.1 and 34.4; m/z 239 (18), $238\left(\mathrm{M}^{+}, 59 \%\right), 209$ (4), 181 (7), 154 (11), 120 (57), 119 (100), 91 (55), 64 (40) and 63 (46). In this last fraction a trace of syn-4,8-dioxo3c,4,7c,8-Tetrahydro-4a,8a-diaza-cyclobuta[1,2-a; 3,4-a']dipentalene (11) (dimer C) could be observed; 1HNMR $\delta 6.80\left(2 \mathrm{H}, \mathrm{d},{ }^{3} \mathrm{~J}=3.0 \mathrm{~Hz}\right), 6.32\left(2 \mathrm{H}, \mathrm{t},{ }^{3} \mathrm{~J}=3.0 \mathrm{~Hz}\right), 6.07\left(2 \mathrm{H}, \mathrm{d},{ }^{3} \mathrm{~J}=3.0 \mathrm{~Hz}\right)$ and 4.09 (4H, m); ${ }^{13} \mathrm{CNMR} d 169.4$ (quat), 136.1 (quat), 119.4, 111.9, 107.2, 47.3 and 32.0.

\section{Small-scale reactions monitored by NMR}

A sample of pyrrolizin-3-one 1 (0.3 to $0.4 \mathrm{mmol})$ in solvent in a quartz NMR tube was irradiated directly with a $125 \mathrm{~W}$ mercury lamp at room temperature. Reaction was monitored by t.l.c. or directly by ${ }^{1} \mathrm{H}$ NMR spectroscopy. The solvent, volume of solvent, reaction time and products formed, with their relative ratios, are indicated.

a. $\left[{ }^{2} \mathrm{H}_{4}\right]$ methanol, $0.7 \mathrm{~mL}, 18 \mathrm{~h}$; dimer A (31\%), dimer B (31\%), dimer C (25\%) and starting material (12\%)

b. $\left[{ }^{2} \mathrm{H}_{3}\right]$ acetonitrile, $0.7 \mathrm{~mL}, 12 \mathrm{~h}$; dimer A (7\%), dimer B (18\%), dimer C (36\%) and starting material $(39 \%)$

c. isopropyl alcohol, $1.0 \mathrm{~mL}, 16 \mathrm{~h}$; dimer A (7\%), dimer B (12\%), dimer C (44\%) and starting material $(36 \%)$.

d. methanol, $1.6 \mathrm{~mL}, 7.5 \mathrm{~h}$ (1 equivalent of benzophenone added); dimer A (39\%), dimer B $(47 \%)$, dimer C (5\%) and starting material (9\%).

\section{References}

1. Flitsch, W.; Neumann, U. Chem. Ber. 1971, 104, 2170.

2. McNab, H.; Thornley, C. Heterocycles 1994, 37, 1977.

3. McNab, H.; Thornley,C J. Chem. Soc., Chem. Commun. 1993, 1570.

4. Anklam, E.; Ghaffari-Tabrizi, R.; Hombrecher, H.; Lau, S.; Margaretha, P. Helv. Chim. Acta 1984, 67, 1402.

5. Anklam, E.; Margaretha, P. Helv. Chim. Acta 1983, 66, 1466.

6. Patjens, J.; Margaretha, P. Helv. Chim. Acta 1989, 72, 1817.

7. Santiago de Alvarenga, E.; Mann, J. J. Chem. Soc., Perkin Trans 1 1993, 2141.

8. Comer, M.C.; Despinoy, X.L.M.; Gould, R.O.; McNab, H.; Parsons, S. Chem. Commun. 1996, 1083. 
9. Fleming,I. Frontier Orbitals and Organic Chemical Reactions; Wiley-Interscience: London, 1976.

10. Kleopfer, R.;Morrison, H. J. Am. Chem. Soc. 1972, 94, 255. 